protection of staff (against a perceived hazard) and the protection of patients (against suboptimal or inadequate health care).

Anthony J Pinching

Department of Clinical Immunology,

London W2 1NY

Michael W ADleR

Academic Department of Genito-Urinary Medicine, Middlesex Hospital Medical School,

London WiN 8AA

RICHARD S TEDDER

Department of Microbiology,

Middlesex Hospital Medical School,
London W1N 8AA

\section{Limited lists of drugs: lessons from abroad}

SIR,-We have learnt that the British government proposes to introduce a more restrictive policy concerning prescribing of medicines under your National Health Service (16 February, p 532). Please allow me to communicate our experience in the Netherlands

At the beginning of 1982 the Dutch sick funds (health insurance organisations) published a non-compulsory advisory compendium for doctors (the Pharmacotherapeutic Kompas), in which detailed information on medicines not recommended for use was printed in red. Later the Dutch government, against our advice, used this publication as the basis for compiling a system of "negative lists" of products which would no longer be reimbursable by the sick funds. These became law in October 1982.

The results of these measures confirmed our predictions. In the preceding years, as a result of various factors, expenditure on medicines increased by $3-6 \%$. In 1982 , however, an increase of $11-12 \%$ took place. This extra increase must be ascribed to altered prescribing habits of doctors, who in some cases changed over to more expensive but reimbursable alternative medicines.

Although overall expenditure in the year of introduction of these limited lists increased by more than the usual average, some companies were badly affected, losing more than $30 \%$ of their turnover, and market conditions were seriously disturbed. There must be better ways to economise on health care costs.

J C SANDERS

Chairman, Voorzitter Nederlandse Associatie van de Farmaceutische Industrie

3565 AC Utrecht

\section{The world cancer burden}

SIR,-Doctors C S Muir and D M Parkin (5 January, p 5) allege, in agreement with many other authorities, "Tobacco is the most important single aetiological factor in cancer in the United States, for example, where cigarette smoking is common, around $30 \%$ of all deaths from cancer may be attributed to the habit." They also claim, citing the United States Surgeon General, that at least $80 \%$ of new cases of lung cancer in developed countries are avoidable.

It is axiomatic that no inferences about cause can be drawn from comparisons of cancer incidence or mortality in self selected smokers, ex-smokers, and non-smokers. Significant positive association determined from case-control or prospective population studies do not necessarily imply cause. It is widely accepted that randomisation is essentia to defeat several types of bias in clinical therapeutic trials. In aetiological studies also, the need for randomised intervention trials to defeat the bias of self selection is becoming increasingly recognised, but many investigators seem to be reluctant to accept some of the more disappointing results that have already emerged.

Two largescale randomised trials have been completed that have an immediate bearing on the claims of Drs Muir and Parkin: the Whitehall study ${ }^{1}$ in London and the multiple risk factor intervention trial ${ }^{2}$ (MRFIT) in the United States. In both trials middle aged men satisfying certain entry criteria were allocated randomly to either the intervention group, which was subjected to intensive advice to abandon smoking, or the normal care group, which was not given such counsel. (In the MRFIT the intervention group also received dietary counsel and stepped care treatment for hypertension with the aim of reducing the risk of ischaemic heart disease.) In both trials the intervention groups achieved substantially greater reductions in smoking than the unplanned reductions in the normal care groups. The average duration of follow up was seven years in MRFIT ${ }^{2}$ and 10 years in the Whitehall study. ${ }^{1}$ Because of the similarity in the designs of the two trials their results can be combined to maximise numbers.

In the low smoking intervention groups 56 cases of lung cancer were recorded in a total starting population of 7142 men $(0 \cdot 78 \%)$, the corresponding numbers for the more heavily smoking normal care groups being 53 in 7169 $(0.74 \%)$. Findings for cancers other than those of the lung were even more surprising. Some 88 cases $(1.23 \%)$ were recorded in the low smoking intervention groups but only 60 cases $(0.84 \%)$ in the normal care groups. Thus in the category "al cancers" there were 144 cases $(2.02 \%)$ in the intervention groups but 113 cases $(1.58 \%)$ in the more heavily smoking normal care groups. Reduced levels of smoking were associated with increases in cancer incidence.

It is not legitimate to perform statistical confidence tests on post hoc hypotheses. However, it is fair to ask Drs Muir and Parkin-and other experts-to explain why these remarkable findings from methodologically reputable trials ${ }^{12}$ conflict so drastically with their claims.

\section{University Department of \\ Medical Physics,
Mersity}

General Infirmary,

1 Rose G, Hamilton PJS, Colwell L, Shipley MJ. A andomized controlled trial of anti-smoking advice: 10-year rest

2 MRFIT Research Group. Multiple risk facto intervention trial: risk factor changes and mortality intervention trial: risk factor chan
results. $\exists A M A 1982 ; 248: 1465-77$.

\section{Mentally ill offenders in prison}

SIR,-While I agree with the general sentiments expressed by your legal correspondent about the high numbers of mentally abnorma offenders being sent to prison ( 9 February, p 447), I think he or she oversimplifies the problem. Firstly, it is not true to say that "despite the years that have passed since the Butler report still nothing has been done." In fact most regions (Oxford being a notable exception) now have plans for medium security facilities and several have fully functioning units. Secondly, the problems posed by mentally handicapped patients are more numerous and more difficult than those posed by mentally ill patients. This is partly because there is now a clear national drive to close mental handicap hospitals and resettle their patients in the community. Thirdly, no one, not even the Butler committee, has yet tackled the problem of the patient who presents chronic behavioural difficulties. The Butler proposals and the subsequent medium security units are directed towards hospital care lasting about one to two years. Fourthly, the developments which are occurring are producing a considerable demand for specialists in several professions. As far as psychiatry is concerned the small supply of senior registrars in forensic psychiatry cannot meet the demands for consultants in this specialty. More fundamentally, university investment in forensic psychiatry and its related disciplines, an essential prerequisite for a healthy specialty, is almost nil.

\section{JOHN GUNN}

Forensic Psychiatry Section,

Institute of Psychiatry
London SE5 $8 \mathrm{AF}$

\section{Preventing infant deaths}

SIR,-Dr Bernard Valman's leading article (2 February, p 339) gives the clear impression that sudden infant deaths would be largely preventable if general practitioners, parents, and paediatricians were more competent or conscientious. His interpretation of the data in the recent multicentre study of postneonatal mortality ${ }^{1}$ differs significantly from our own on the following points.

(1) Dr Valman fails to draw attention to the poor correlation between clinical and postmortem findings in the study. Full necropsy and clinica evidence was available for 351 children dying from causes other than congenital lesions, prematurity, trauma, and neoplasia. Only 124 out of these 35 had necropsy evidence of a disease deemed severe enough to have caused death on its own. Of these, only 48 also had clinical features corresponding to the pathological findings at necropsy. Arguably only these 48 could have been saved by improvements in clinical care; these represent 1 in 7 of sudden infant deaths.

(2) Dr Valman argues that there exist "undoubtedly sinister symptoms," attention to which could prevent deaths in infancy. The study reports, however, that 132 of the 351 children had no symptoms before death. A further 74 had nonspecific symptoms, which are often presented to the general practitioner. ${ }^{2-4} \mathrm{Dr}$ Valman believes that changes in breathing, poor feeding, and irritability may be particularly important. He states that we do not know how common such symptoms are in the community, but those of us in general practice have no doubt that they are very common. In a recent study from Newcastle, irritability was reported in $65 \%$ of consultations in infants. ${ }^{5}$ Many symptoms in infants are also transient and the problem of interpretation presents difficulties for the primary care doctor who has to adopt a "wait and see" policy in most cases. The recommendation that all children with such symptoms should be seen by a member of the paediatric unit is clearly unrealistic.

(3) The leader begins with a statement that is both clear and distressing: "Two thirds of the 131 infants seen by general practitioners . . . had received inadequate management." It omits to point out that this judgment was made retrospectively by case conferences in the light of the children's subsequent death. The conclusions would carry more credibility if controls had been included and the case conference had reviewed the histories blind. The original report acknowledges that there is no guarantee that "adequate" management would have had any effect on the outcome.

On these shaky foundations, Dr Valman builds a precarious structure of recommendations, two of them contradictory: that mothers be taught to recognise important symptoms and manage them (presumably by a means other than immediate admission to 
hospital), and that it is unfair and may be dangerous to leave decisions about follow up to these same mothers. He also proposes that children under 6 months should be seen monthly by health visitors. As a means of preventing infant deaths such visits remain controversial; they will certainly reduce the time available for health visitors to seek out children who do not attend at routine clinics.

Dr Valman deals at length with policies for secondary prevention but neither the recent multicentre study nor any other has convincingly defined sensitive and specific clinical predictors of sudden infant death. The report itself concludes that primary prevention might be most effective and suggests that the policies which are likely to improve postneonatal mortality are those aimed at reducing accidents and infections in infancy and smoking in mothers, encouraging breast feeding, and improving socioeconomic conditions.

DAVID JeWELL

Peter Burke ANN LOUISE KINMONTH D J G BAIN Aldermoor Health Centre,
Southampton SO1 6ST

1 Knowelden J, Keeling J, Nicholl JP. A multi-centre study of post neonatal mortality. London: Departstudy of post neonatal mortality. London:

2 Pollak M. Child care. In: Fry J, ed. Trends in general practice 1977. London: Royal College of General Practitioners, 1977

3 Royal College of General Practitioners. Morbidity statistics from general practice 1971-2. Second national study. London: HMSO, 1979.

4 Hart C, ed. Child care in general practice. Edinburgh: Churchill Livingston, 1982

5 Wilson AD, Downham MAPS, Forster DP. Acute illness in infants: a general practice study. $\mathcal{F} R$

SIR,-When commenting on the Knowelden study of postneonatal mortality ${ }^{1}$ Dr Bernard Valman (2 February, p 339) is incorrect to imply that there is no information on the prevalence of symptoms in infants. A preliminary report ${ }^{2}$ documented symptoms in those who suffered cot deaths and controls ${ }^{2}$ : $59 \%$ of cases and $26 \%$ of controls had minor symptoms in the preceding week $(48 \%$ and $12 \%$ had major symptoms). With a low incidence of cot death, estimated for clinically "unexpected" and "terminal disease" cases at $28 /$ year/10000 children at risk, ${ }^{1}$ this means that symptoms have minimal predictive value. Only one child in 23000 with minor symptoms (and one in 4800 with major symptoms) can be expected to die in the following week. Obviously it is neither feasible nor desirable to admit every such baby to hospital, so parents, general practitioners, and health visitors are placed in great difficulty when managing mild illness in a baby under 6 months. The addition of risk factors does, however, give guidance towards early treatment and admission. For this reason alone there is good reason to retain risk scoring as a clinical tool for primary care workers, though such scores will need local adjustments.

The study argues that breast feeding is protective and smoking in pregnancy causative for cot deaths. The case remains unproved for both. Bottle feeding has a low relative risk and is heavily confounded by social factors. Smoking has a higher risk but no dose-response relation. Though it lowers birth weight, this is not how smoking affects mortality. ${ }^{1}$ Pregnant women are now choosing to smoke less; probably those who continue to smoke are an exceptional group and so smoking in pregnancy is becoming a stronger marker for social disadvantage.

Four national newspapers, aided by an uninformative DHSS press release, stated that the study proved that bottle feeding and smoking caused "cot deaths." After dismissing child abuse as a substantial factor it would be unfortunate if the study only increased the guilt of smoking or bottle feeding mothers who had suffered a tragedy.

This must not be the end of cot death studies. The authors have completed a very difficult task. Their reward should be to see their work used as a model for every health district. I would nominate Sheffield to coordinate such an enterprise and hope the DHSS will foot the bill.

ANGUS Nicoli

London School of Hygiene and Tropical Medicine, London WC1E 7HT

1 Knowelden J, Keeling J, Nicholl JP. A multi-centre study of post neonatal mortality. London: Department of Health and Social Security, 1985.

2 Stanton AN, Downham MAPS, Oakley JR, Emer $\mathrm{JL}$, Knowelden J. Terminal symptoms in childre dying suddenly and unexpectedly at home. $\mathrm{Br} \mathrm{Med}$ f 1978;ii:1249-51.

SIR,-I would like to comment on Dr Bernard Valman's leading article (2 February, p 339). Despite the lead taken by the Royal College of General Practitioners, child health services in the UK remain fragmented. Many infants are weigled, immunised, and seen with nonacute medical problems in child health clinics, seeing the general practitioner only with acute illnesses. Often communication between the general practitioner and the clinical medical officer or health visitor is poor, and consequently the information about these infants is fragmented, making identification of those at risk of postneonatal death more difficult.

Dr Valman comments that sinister symptoms are an indication for a child to be seen by a member of the paediatric unit, who may or may not admit the child. Unfortunately, outside the teaching hospitals and centres of excellence such as Northwick Park these units are staffed almost exclusively by senior house officers with cover from the consultants. Are the paediatric consultants in these units prepared to attend all these infants in the receiving room and decide who should be admitted for observation overnight? More often than not the practitioner referring the child has more paediatric experience than the senior house officer assessing the infant, and if all those with sinister symptoms were admitted for observation the present facilities would be overwhelmed. Unfortunately even admission to hospital does not always prevent the sudden infant death syndrome.

Obviously all doctors dealing with infants should be taught how to assess them objectively for serious disease. I would suggest, however, that the study confirms the need for general practitioners with a special interest in paediatrics, as advocated in the Court report of 1977. Within group practiçes these doctors would organise child welfáre clinics along with attached health visitors for their practice population. Information would not be fragmented, and those infants thought to be of high risk could be identified, and, one hopes, some of these unfortunate deaths prevented.

STEPHEN HODGES

Headingley Medical Centre Leeds LS6 3DS
Failure of single dose amoxycillin as prophylaxis against endocarditis

SIR,-The recent report of an alleged case of failure of amoxycillin prophylaxis against endocarditis has stimulated correspondence about penicillin tolerant streptococci causing endocarditis after dental procedures. Dr D W Denning and Dr W S Hillis (26 January, $p$ 317 ) are mistaken to imply that giving probenecid concurrently with single dose amoxycillin is not relevant to the problem of endocarditis caused by streptococci tolerant to amoxycillin.

A difficulty arises when a patient has not had penicillin recently and an "unexpected" bacteraemia with amoxycillin tolerant streptococci follows a dental procedure. Single dose amoxycillin sometimes still prevents endocarditis in this situation as the antibiotic may interfere with the tolerant streptococci sticking to and multiplying on a heart lesion. However, when an enormous inoculum of tolerant streptococci enters the blood the chances of prophylaxis being successful are increased by prolonging the period during which tolerant bacteria are inhibited, as has been shown in some animal studies. ${ }^{12}$ The concurrent administration of $1 \mathrm{~g}$ oral probenecid with a single $3 \mathrm{~g}$ oral dose of amoxycillin results in more persistent serum amoxycillin concentrations. ${ }^{3}$ Therefore, if probenecid were to be recommended together with the single dose of amoxycillin one hour before dental extractions successful prophylaxis against endocarditis might be expected even when a large dose of amoxycillin tolerant streptococci enters the blood.

Incidentally, the simplicity, clinical effectiveness, and lack of toxicity of amoxycillin given together with probenecid has been shown in another situation where organisms with reduced sensitivity to penicillins have to be considered-for the single dose treatment of patients with gonorrhoea.

D C SHANSON

Department of Medical Microbiology, Charing Cross and Westminster Medical School,
London SW1P 2AR

\section{Glauser MP, Bernard JP, Moreillon P, Francidi P. Successful single-dose amoxycillin prophylaxis against experimental streptococcal endocarditis: Infect Dis 1983;147:568-75. \\ 2 McGowan DA, Nair S, MacFarlane TW, MacKenzie $D$. Prophylaxis of experimental endocarditis in rabbits using one or two doses of amoxycillin. $\mathrm{Br}$ Dent $\mathcal{F} 1983 ; 155: 88-90$ \\ 3 Shanson DC, McNabb R, Hajipieris P. The effect of probenecid on serum amoxycillin concentrations up to 18 hours after a single $3 \mathrm{~g}$ oral dose of endocarditis. F Antimicrob Chemother 1984;13: 629-32.}

**This correspondence is now closed.-ED, $B M F$.

\section{Can we afford screening for neural} tube defects?

SIR,-Two reports have questioned the wisdom of continuing regional screening programmes for neural tube defects based on maternal serum $\alpha$ fetoprotein values. ${ }^{2}$ One centre, in an area of low incidence, found serum $\alpha$ fetoprotein values to have poor predictive value in detecting open neural tube defects and abandoned the programme after screening 3479 pregnancies. ${ }^{1}$ The other study, in a high incidence area, found an efficacy (proportion of open neural tube defects in fetuses of women who underwent terminations 